\title{
Subclinical hypothyroidism in addition to common risk scores for prediction of cardiovascular disease: a 10-year community-based cohort study
}

\author{
Tae Hyuk Kim, Hoon Sung Choi, Ji Cheol Bae', Jae Hoon Moon ${ }^{2}$, Hyung-Kwan Kim, \\ Sung Hee Choi ${ }^{2}$, Soo Lim ${ }^{2}$, Do Joon Park, Kyong Soo Park, Hak Chul Jang', \\ Moon-Kyu Lee', Nam H Cho ${ }^{3}$ and Young Joo Park \\ Department of Internal Medicine, Seoul National University College of Medicine, 101 Daehak-ro, Jongno-gu, Seoul \\ 110-744, Korea, 'Department of Medicine, Samsung Medical Center, Sungkyunkwan University School of Medicine, \\ Seoul, Korea, ${ }^{2}$ Department of Internal Medicine, Seoul National University Bundang Hospital, Seongnam, Korea, \\ ${ }^{3}$ Department of Preventive Medicine, Ajou University School of Medicine, \#5 Wonchon-Dong, Youngtong-Gu, \\ Suwon 442-749, Korea
}



\begin{abstract}
Objective: This study was carried out to determine whether serum TSH levels improve the prediction of cardiovascular risk in addition to common clinical risk scores, given the association between subclinical hypothyroidism (SCH) and cardiovascular disease (CVD).

Design: We carried out an observational study in a prospective cohort.

Methods: The study included a total of $344 \mathrm{SCH}$ and 2624 euthyroid participants aged over 40 years and who were without previously recorded CVDs were included in this study analysis. We measured thyroid function and traditional risk factors at baseline and estimated the 10-year cumulative incidence of CVD in a gender-stratified analysis.

Results: During 10 years of follow-up, 251 incident cardiovascular events were recorded. The elevation of serum TSH levels significantly increased the CV risk independent of conventional risk factors in men. In the atherosclerotic CVD (ASCVD) risk score or the Reynolds risk score (RRS) model, the addition of serum TSH levels had no effect on model discrimination as measured by the area under the curve in either women or men. Adding serum TSH did not improve the net reclassification improvement in either women $(3.48 \%(P=0.29)$ in the ASCVD, $-0.89 \%(P=0.75)$ in the RRS, respectively) or men $(-1.12 \%$ ( $P=0.69), 3.45 \%(P=0.20)$, respectively) and only mildly affected the integrated discrimination Improvement in the
\end{abstract} ASCVD-adjusted model $(0.30 \%$ in women and $0.42 \%$ in men, both $P=0.05)$.

Conclusions: In the context of common risk scoring models, the additional assessment of serum TSH levels provided little incremental benefit for the prediction of CV risk.

\section{Introduction}

Cardiovascular disease (CVD), which is a major health problem worldwide, is the leading cause of death in the United States (1) and the second primary cause of death in Korea (2). In clinical practice, several clinical risk factors that can be easily measured are powerful predictors of
CVD $(3,4)$. However, current prediction models cannot anticipate certain cases of incident CVD, thus motivating better prediction of the risk with alternative biomarkers.

Growing evidence indicates that higher serum thyroid-stimulating hormone (TSH) levels, even within
(C) 2014 European Society of Endocrinology Printed in Great Britain
Published by Bioscientifica Ltd. 
the reference range, are associated with worsening blood pressure (5) and lipid levels (6). Indeed, subclinical hypothyroidism (SCH), which is defined as an isolated elevation of TSH levels, is a quite common condition that occurs in $4-20 \%$ of the population (7); it is increasingly being recognised because thyroid function testing has been increased substantially in primary care (8). A recent large Taiwanese study has reported that $\mathrm{SCH}$ carried with it a $68 \%$ increased risk for CV mortality during a 10 -year follow-up period (9). Despite the intuitive appeal of the relationship between TSH elevation or SCH and adverse $\mathrm{CV}$ outcomes, whether TSH testing would lead to an improvement in the prediction of CVD has not been established.

In this study, we sought to estimate the extent to which the inclusion of TSH can improve the risk stratification of clinical risk scores in a large, prospective, community-based cohort with different levels of overall CVD risk in a gender-stratified analysis.

\section{Subjects and methods}

\section{Study population}

The design of the Ansung cohort study and the demographics of participants have been described elsewhere (10). This ongoing, prospective cohort study is part of the Korean Health and Genome Study, which is a communitybased epidemiological survey to investigate trends in chronic noncommunicable diseases and associated risk factors. The baseline examination was performed in 2001-2002, and the biennial follow-up examination is ongoing. The eligibility criteria included the following variables: age of 40-69 years, residence located within the border of the survey area for at least 6 months before testing, and sufficient mental and physical ability to participate in the study. A total of 5018 participants were recruited from the residents of Ansung, a representative rural farming community, using a two-stage clustersampling method stratified by age, sex, and residential district. Among the total participants, 3501 provided baseline blood samples that were stored in liquid nitrogen until the time of analysis to perform the thyroid function test (11). The excluded group was similar in gender ratio but slightly older than the study group $(56.0 \pm 8.7$ vs $55.3 \pm$ 8.9 years; $P=0.02$ ).

We excluded 293 participants: subjects with a clinical history of CVD at baseline; those without follow-up data on CVD or mortality; those taking thyroxine, antithyroid agents, or medications that might interfere with thyroid function (i.e. amiodarone, antidepressants, and hormonal replacement); or those who had suffered from liver cirrhosis or cancer (12). Among the 3004 participants remaining, 344 (11.5\%) participants with SCH and 2624 (87.4\%) participants with euthyroidism at baseline were included in the final analysis. The proportion of participants lost to follow-up in the study population was similar to that in the total population (data not shown). Of the 36 excluded patients, six patients had overt thyroid dysfunction, and 30 (1.0\%) patients had subclinical hyperthyroidism. Information about thyroid medication was extracted from the structured questionnaires at the follow-up visits.

As prior studies have shown the $\mathrm{CV}$ risks based on the degree of $\mathrm{SCH}$, participants were categorised with regard to the degree of TSH elevation as exhibiting mild (4.1-6.9 mIU/1) and moderate/severe $(\geq 7.0 \mathrm{mIU} / \mathrm{l})$ degrees of elevation $(13,14)$. To assess the effect of TSH elevation on global CVD risk prediction over 10 years, we considered two widely cited and validated risk scores: the atherosclerotic CVD (ASCVD) risk score from the 2013 American College of Cardiology and the American Heart Association guidelines on the treatment of blood cholesterol (4) and the Reynolds risk score (RRS) (3), a model that includes additional information on biomarkers and data on family history. To mimic clinical practice, we used the published computational formulas for a 10-year cumulative risk rather than a refitted model using the ASCVD and the RRS covariates. Informed written consent was obtained from all of the participants. The study protocol was approved by the ethics committee of the Korean Center for Disease Control and the Ajou University School of Medicine Institutional Review Board.

\section{Measurements of laboratory and anthropometric parameters}

Each participant completed a structured questionnaire that included health-related questions concerning history of diabetes, hypertension, current smoking status and pharmaceutical information. Anthropometric parameters and blood pressure values were measured using standardised methods. The fasting plasma concentrations of glucose (reference range $74-106 \mathrm{mg} / \mathrm{dl}$ ), total cholesterol (<200 mg/dl), HDL cholesterol (40-60 mg/dl), highsensitivity C-reactive protein $(<1.0 \mathrm{mg} / \mathrm{l})$ and standardised HbA1c (3.5-6.4\%) were measured in a central laboratory. All of the participants underwent a $75 \mathrm{~g}$ oral glucose tolerance test (OGTT) at baseline. Diabetes was defined according to the American Diabetes Association criteria 
(15) based on the $75 \mathrm{~g}$ OGTT results, HbA1c $\geq 6.5 \%$, or current treatment with oral antidiabetic medications or insulin. Hypertension was defined as systolic blood pressure $\geq 140 \mathrm{mmHg}$, diastolic blood pressure $\geq 90 \mathrm{mmHg}$, or taking antihypertensive medication. Current smokers are defined as persons who reported smoking regularly during the previous 6 months.

The concentrations of serum $\mathrm{TSH}$, free $\mathrm{T}_{4}$, and antithyroid peroxidase (TPO) antibody were measured according to the following methods (11). TSH was determined by IRMA and had an analytical sensitivity of $0.04 \mathrm{mIU} / 1$ (TSH-CTK-3, DiaSorin SpA, Saluggia, Italy). Free $\mathrm{T}_{4}$ was measured by RIA and had an analytical sensitivity of 0.05 ng/dl (RIA-gnost FT4, Cisbio Bioassays, Codolet, France). SCH was defined as TSH $\geq 4.1 \mathrm{mIU} / 1$ with a normal free $\mathrm{T}_{4}$ range $(0.7-1.8 \mathrm{ng} / \mathrm{dl})$, and euthyroidism was defined as a normal TSH range (0.4-4.0 mIU/1). The concentration of anti-TPO antibody was measured by the RIA kit (RSR Ltd, Pentwyn, UK; normal range <0.3 mIU/l). The participants with an anti-TPO antibody concentration above the normal range were defined as anti-TPO antibody-positive cases.

\section{Evaluation of cardiovascular outcome}

Study participants were monitored through December 2012 to determine the 10-year cumulative incidence of CVD events and all-cause mortality. A CVD event was defined as being diagnosed with myocardial infarction, angina, stroke, or CVD death by a physician at the participant's clinical centre. Ascertainment of outcome was determined by direct interview and telephone contact during the prescheduled biennial visits and at the end of 10 years of follow-up. For deceased participants, additional information was gathered through visits with neighbours and visits to the district government mortality offices.

\section{Statistical analysis}

Continuous variables are expressed as the mean \pm s.D. or as median (IQR) values, and categorical variables are presented as absolute counts and percentage. The hazard ratios (HRs) and 95\% CIs of TSH levels (both in categorised and continuous variables) for the CVD events were calculated using gender-stratified Cox proportional hazard models, first unadjusted and subsequently adjusted for the two risk scores. We used unconditional logistic regression models to calculate the cumulative incidence function at the 10-year follow-up for each participant (16). We formally tested for interactions by including a product term between the risk scores and serum TSH level in the regression models and found that there was no evidence of any significant interaction. In addition, we performed lag time analysis to investigate the possible reverse causality (CVD leading to $\mathrm{SCH}$ ) by relating baseline thyroid function testing with CVD incidence for a 2-year latency period between TSH measurement and the start of the at-risk period (17).

Using the area under the curve (AUC) of receiveroperating characteristic (ROC) curves, we evaluated the discriminatory capacity of the model that included TSH levels compared with the model without TSH levels. Model calibration across deciles of predicted risk was tested by a Hosmer-Lemeshow goodness-of-fit test. We assessed risk reclassification by sorting the predicted 10-year risk for each model into three categories ( 0 to $<10 \%$, 10 to $<20 \%$, and $\geq 20 \%$ ). We evaluated risk reclassification using TSH levels according to the method developed by Pencina et al. (18) for determining the net reclassification improvement and the integrated discrimination improvement. Statistical analysis was performed using SPSS for Windows (version 19.0, IBM, Armonk, NY, USA). A $P$ value $<0.05$ was considered to be statistically significant.

\section{Results}

The baseline clinical characteristics of 2624 euthyroid (1363 women and 1261 men) and 344 SCH (267 women and 77 men) participants stratified by gender are presented in Table 1. Significant differences in thyroid status were observed for smoking status in both women and men, and significant differences in free $\mathrm{T}_{4}$ levels, anti-TPO antibody positivity and BMI were observed in women only. Compared with the euthyroid men, men with SCH were significantly older and more likely to suffer hypertension and diabetes. Through the end of the 10-year follow-up, there were a total of 251 (8.5\%) CV events: 31 myocardial infarction cases, 100 angina cases, 83 stroke cases and 37 CVD death cases. The number of patients who used thyroid medications during follow-up was not different between the event group and the non-event group (3 (1.2\%) and $36(1.3 \%)$ respectively). We included nine subjects (one in the SCH group and eight in the euthyroid group) who reported a medication history for dyslipidaemia at baseline because an analysis of the exclusion of the subjects did not reveal any differences (data not shown).

The cumulative incidence of $\mathrm{CV}$ events increased with increasing TSH levels in men (8.3\%, 0.4-4.0 mIU/1; 16.1\%, 4.1-6.9 mIU/1; and 26.7\%, $\geq 10.00 \mathrm{mIU} / \mathrm{l}$ ) but not in women (Table 2, and Supplementary Figure 1, see section 
Table 1 Baseline characteristics of the study population according to the thyroid status.

\begin{tabular}{|c|c|c|c|c|c|c|}
\hline & \multicolumn{3}{|c|}{ Women } & \multicolumn{3}{|c|}{ Men } \\
\hline & $\mathrm{SCH}(n=267)$ & Euthyroid $(n=1363)$ & $P$ & $\mathrm{SCH}(n=77)$ & Euthyroid $(n=1261)$ & $P$ \\
\hline Age, mean (s.D.) (years) & $56.0(9.2)$ & $55.1(9.0)$ & 0.13 & $58.9(8.4)$ & $54.9(8.7)$ & $<0.01$ \\
\hline TSH, median (IQR) (mIU/l) & $5.3(4.6-6.8)$ & $2.1(1.4-2.9)$ & & $5.2(4.5-6.5)$ & $1.6(1.1-2.2)$ & \\
\hline Free T4, mean (s.D.) (ng/dl) & $0.9(0.1)$ & $1.0(0.1)$ & $<0.01$ & $1.0(0.1)$ & $1.0(0.1)$ & 0.33 \\
\hline Anti-TPO antibody-positivity, $n(\%)$ & $68(25.5)$ & $132(9.7)$ & $<0.01$ & $8(10.4)$ & $65(5.2)$ & 0.06 \\
\hline Hypertension, $n(\%)$ & $64(24.0)$ & $329(24.1)$ & 0.95 & $21(27.3)$ & $225(17.8)$ & 0.04 \\
\hline Diabetes mellitus, $n(\%)$ & $39(14.6)$ & $183(13.4)$ & 0.61 & $17(22.1)$ & $172(13.6)$ & 0.04 \\
\hline Current smoker, $n(\%)$ & $1(0.4)$ & $63(4.6)$ & $<0.01$ & $31(40.3)$ & $693(55.0)$ & 0.01 \\
\hline $\begin{array}{l}\text { Parental history of premature CAD, } \\
n(\%)\end{array}$ & 0 & 0 & - & 0 & $2(0.2)$ & 1.00 \\
\hline SBP, mean (S.D.) (mmHg) & $123.4(19.6)$ & $122.5(19.1)$ & 0.47 & $125.3(17.6)$ & $121.5(17.0)$ & 0.06 \\
\hline DBP, mean (s.D.) (mmHg) & $78.4(11.2)$ & $77.7(10.5)$ & 0.31 & $79.1(9.4)$ & $78.8(10.1)$ & 0.79 \\
\hline BMI, mean (s.D.) $\left(\mathrm{kg} / \mathrm{m}^{2}\right)$ & $25.4(3.4)$ & $24.9(3.4)$ & 0.03 & $23.4(3.3)$ & $23.9(3.1)$ & 0.12 \\
\hline \multicolumn{7}{|l|}{ Cholesterol, mean (s.D.) (mg/dl) } \\
\hline Total & $196.7(38.1)$ & $195.7(35.5)$ & 0.67 & $186.0(41.5)$ & $187.8(35.3)$ & 0.66 \\
\hline LDL & $122.5(39.2)$ & $120.3(33.7)$ & 0.33 & $107.8(43.2)$ & $112.1(38.9)$ & 0.36 \\
\hline $\mathrm{HDL}$ & $47.3(10.0)$ & $48.0(11.3)$ & 0.32 & $45.2(9.2)$ & $46.9(11.6)$ & 0.14 \\
\hline HbA1c, mean (s.D.) (\%) & $5.6(0.9)$ & $5.6(0.9)$ & 0.75 & $5.9(1.4)$ & $5.6(0.9)$ & 0.11 \\
\hline $\begin{array}{l}\text { C-reactive protein, median (IQR) } \\
(\mathrm{mg} / \mathrm{l})\end{array}$ & $1.6(0.8-2.5)$ & $1.5(0.8-2.5)$ & 0.51 & $1.8(1.1-3.6)$ & $1.6(0.8-2.7)$ & 0.15 \\
\hline
\end{tabular}

CAD, coronary artery disease; DBP, diastolic blood pressure; SBP, systolic blood pressure; SCH, subclinical hypothyroid; TPO, thyroid peroxidase; TSH, thyroidstimulating hormone.

on supplementary data). The cardiovascular hazards associated with increasing TSH categories were observed in both the ASCVD-adjusted and the RRS-adjusted models (both $P<0.01$ for trend) in men. When we analysed the TSH levels as continuous variables, the $\mathrm{HR}$ of $\mathrm{CV}$ events per 1-S.D. increase in TSH levels was $1.19(P<0.01)$ in the ASCVD-adjusted model and $1.24(P<0.01)$ in the RRSadjusted model in men. As expected, the group of individuals older than 65 years suffered more CV events than the younger group ( 13.6 vs $7.1 \%, P<0.01)$. When we further stratified the subjects according to the age categories, this gender difference was decreased in older adult (Supplementary Table 1, see section on supplementary data). The presence of anti-TPO antibody did not affect the HR of $\mathrm{CV}$ events (Table 2). The association between TSH levels and CVD risk was unchanged when we performed stratified analyses for diabetes and BMI categories (classified as BMI $<25,25-30,>30 \mathrm{~kg} / \mathrm{m}^{2}$ ) ( $P=0.19$ for diabetes and 1.00 for BMI categories). When a 2-year lag period was imposed between TSH measurements and start of the at-risk period, the results were similar to the non-lagged analyses (data not shown).

Figure 1 displays ROC curves for prediction of a 10-year cumulative incidence of $\mathrm{CV}$ events. The addition of the TSH value to either the ASCVD or the RRS did not improve the discriminatory ability of the risk model applied in either women (ROC-AUC, 0.669-0.667 ( $P=0.95$ for difference) and $0.672-0.672$ ( $P=1.00$ for difference), respectively) or men (0.669-0.681 ( $P=0.72$ for difference) and 0.660-0.671 ( $P=0.75$ for difference), respectively). Both the ASCVD and the RRS with TSH information remained calibrated.

The net reclassification and integrated discrimination improvement, as markers of improved risk reclassification obtained by means of TSH levels, are given in Table 3 . Adding serum TSH did not improve the net reclassification improvement in either women $(3.48 \%(P=0.29)$ in the ASCVD, $-0.89 \%(P=0.75)$ in the RRS, respectively) or men $(-1.12 \%(P=0.69), 3.45 \%(P=0.20)$, respectively $)$ and only mildly affected the integrated discrimination improvement in the ASCVD-adjusted model $(0.30 \%$ in women and $0.42 \%$ in men, both $P=0.05$ ).

\section{Discussion}

In this community-based prospective cohort followed for 10 years, we observed that an elevation of serum TSH levels significantly increased the CV risk by $20 \%$ per 1-s.D. increase independent of conventional CV risk factors in men. However, when the information on TSH was included to predict the risk of CVD either with the ASCVD model or the RRS model, the predictability of each risk scoring model was not improved in either women or men. This finding suggests that there was no additional benefit afforded by screening for TSH when using the preexisting clinical scoring models to predict the CV risk, despite their association. 
This study has clinical relevance because there is insufficient evidence to recommend for or against routine screening for subclinical thyroid dysfunction $(19,20)$, whereas measurement of serum TSH is one of the most frequently ordered tests in primary care (21). Based on the need for aggressive case finding, a previous consensus statement from three different academic committees favoured routine screening for subclinical thyroid dysfunction in the general population until adequate data are accumulated (22). To the best of our knowledge, this report is the first prospective study that demonstrates that an isolated TSH elevation would not be an efficient discriminator of $\mathrm{CV}$ risk in asymptomatic individuals.

A possible explanation for this finding is that $\mathrm{SCH}$ increases the $\mathrm{CV}$ risk particularly in men; however, its impact is not as large compared with other metabolic derangements, such as dyslipidaemia, diabetes, and hypertension (23), for which management is already a part of standard care targeted at reducing CV risk. That is, those phenotypic risk factors are considerably stronger determinants of adverse $\mathrm{CV}$ events compared with $\mathrm{SCH}$ (24). Thus, the predictive power gained from the expanded TSH screening, if any, might not have an additional effect on the clinical risk factors commonly used in adults.

A previous meta-analysis of 55287 individuals from 11 prospective cohorts reported an increased risk of coronary heart disease events and mortality in individuals with moderate/severe $\mathrm{SCH}$ (13). It is possible that as more independent CVD risk factors are included, the risk estimate improves; however, a significant statistical association does not necessarily lead to an improvement in the risk stratification for $\mathrm{CV}$ outcomes. By considering the TSH levels to be continuously distributed risk factors for a composite of adverse CV outcomes, our data extend these studies to demonstrate that the ability of serum TSH to differentiate subjects who do and do not develop CVD is minimal after consideration of other common risk factors. However, there is a likelihood that TSH levels might contribute more to the subsets of men with moderate/ severe SCH or older adult, as can be inferred from the stratified analysis. In our previous reports, SCH subjects with intermediate to high risk (Adult Treatment Panel-III $\geq 10 \%$ ) had higher coronary artery calcium scores than euthyroid subjects, especially in men (25). Marfella et al. (26) observed more inflammatory activity in the asymptomatic carotid plaques of $\mathrm{SCH}$ subjects than in euthyroid subjects. Of note, the negative effect of $\mathrm{SCH}$ on $\mathrm{CV}$ events may vanish in the oldest elderly individuals ( $>80-85$ years) with overwhelming comorbidities other than $\mathrm{SCH}$ $(27,28)$. 

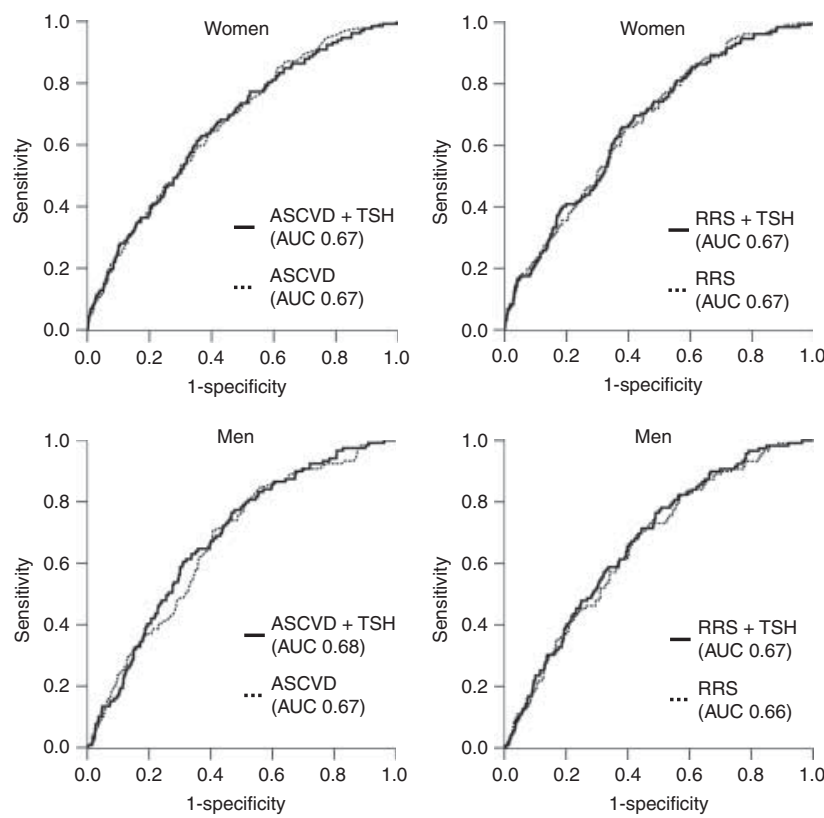

\section{Figure 1}

Receiver-operating characteristic curves for the atherosclerotic cardiovascular disease (ASCVD) risk score and Reynolds risk score (RRS) model with and without TSH levels. AUC, area under the curve; $\mathrm{TSH}$, thyroid-stimulating hormone.

The reported benefits of SCH treatments were limited. Garber et al. (29) reported that the treatment benefit for those with screen-detected SCH is uncertain in the TSH range of 4.0-10.0 mIU/1 outside of pregnancy. In 2007, a Cochrane review assessed 12 randomised controlled trials of thyroxine replacement in patients with SCH and concluded that treatment did not result in improved survival, reduced CV mortality, or improved healthrelated quality of life (30), whereas new data exist for improved outcomes of coronary heart disease in younger ( $<70$ years), but not older, patients treated with thyroxine (31). Furthermore, SCH was associated with improved survival in a study of the elderly aged 85 years (28); any benefits may be offset by the potential adverse effects of replacement therapy, such as atrial fibrillation and osteoporosis, because the elderly are particularly susceptible to atrial fibrillation (32). In addition, postmenopausal women are prone to accelerated bone loss (29). Taken together with the present study, population screening for SCH should not be generalised but should be selectively applied only to the subjects who are expected to achieve an improved predictability of $\mathrm{CV}$ risk or benefit from thyroxine supplementation for SCH.
The difference in the impact of SCH between women and men with respect to $\mathrm{CV}$ outcomes has been reported in a few studies that presented gender-specific data (27). In a Danish cross-sectional study, $\mathrm{SCH}$ was a significant predictor of $\mathrm{CV}$ disease in young men aged less than 50 years (33). However, the gender differences were not observed in the study of 1101 older individuals aged more than 65 years (34). Consistent with previous studies, the risk of $\mathrm{CV}$ events was increased relative to increasing TSH categories in men, and it can be inferred from the baseline observation that men with SCH were more likely to have an adverse CV risk profile than women with SCH. This gender difference was evident in younger adult groups in our study, corresponding with the reduced SCH-associated $\mathrm{CV}$ risk in premenopausal women (35).

The current study has several strengths. The results came from a large, prospective, community-based cohort. There was a substantial number of CV events in the euthyroid and SCH groups during the 10 years of followup. We adapted new reclassification statistics, which are useful adjunct measures of discrimination in prospective data for quantifying the net increase vs the decrease in risk categories among case patients minus that among control participants (36). We also reported independence in multivariable regressions, discrimination in the AUC and calibration to describe the clinical contribution of TSH measurements in accordance with recent recommendations (37).

This study also has a number of weaknesses. First, the study was carried out in an area where there was sufficient iodine in a population of homogeneous Korean ethnic background; thus, these results might have limited applicability in areas where iodine is deficient, and caution is needed in extrapolating the study results to other ethnic groups. Second, we could not obtain results for subclinical hyperthyroidism because of its low prevalence in this iodine-sufficient population $(38,39)$. Because subclinical hyperthyroidism has been suggested to be associated with coronary artery disease (40) or stroke (41), we excluded this condition to avoid complexity in the analysis of two different conditions with limited statistical power. Third, among 26 patients with SCH and TSH higher than $10.0 \mathrm{mIU} / 1$ in our cohort, four patients developed CVD during follow-up, and only two patients who did not develop CVD used thyroid medications during follow-up. Generally, patients with severe $\mathrm{SCH}$ are recommended to be treated with thyroxine, as there is a consensus in its ability to reduce $\mathrm{CV}$ risk in younger patients aged less than 65-70 years (42). Using stored blood samples, we could not explain to 
Table 3 Reclassification of 10-year cardiovascular risk according to the thyroid status for subjects in whom cardiovascular disease developed and for those in whom cardiovascular disease did not develop.

\begin{tabular}{|c|c|c|c|c|c|c|c|c|}
\hline \multirow[b]{2}{*}{ Models without TSH } & \multicolumn{4}{|c|}{ ASCVD model with TSH } & \multicolumn{4}{|c|}{ RRS model with TSH } \\
\hline & $\begin{array}{l}0 \text { to }<10 \% \\
\text { risk }\end{array}$ & $\begin{array}{c}10 \text { to }<20 \% \\
\text { risk }\end{array}$ & $\begin{array}{l}\geq 20 \% \\
\text { risk }\end{array}$ & $\begin{array}{l}\text { Total no. } \\
\text { at risk }\end{array}$ & $\begin{array}{l}0 \text { to }<10 \% \\
\text { risk }\end{array}$ & $\begin{array}{l}10 \text { to }<20 \% \\
\text { risk }\end{array}$ & $\begin{array}{l}\geq 20 \% \\
\text { risk }\end{array}$ & $\begin{array}{l}\text { Total no } \\
\text { at risk }\end{array}$ \\
\hline \multicolumn{9}{|l|}{ Women } \\
\hline \multicolumn{9}{|c|}{ Subjects in whom CVD developed } \\
\hline 0 to $<10 \%$ risk & 74 & 10 & 0 & 84 & 68 & 6 & 0 & 74 \\
\hline 10 to $<20 \%$ risk & 5 & 39 & 4 & 48 & 6 & 43 & 2 & 51 \\
\hline$\geq 20 \%$ risk & 0 & 0 & 0 & 0 & 0 & 0 & 7 & 7 \\
\hline Total no. & 79 & 49 & 4 & 132 & 74 & 49 & 9 & 132 \\
\hline \multicolumn{9}{|c|}{ Subjects in whom CVD did not develop } \\
\hline 0 to $<10 \%$ risk & 1154 & 85 & 0 & 1239 & 1063 & 56 & 0 & 1119 \\
\hline 10 to $<20 \%$ risk & 41 & 212 & 6 & 259 & 27 & 328 & 9 & 364 \\
\hline$\geq 20 \%$ risk & 0 & 0 & 0 & 0 & 0 & 2 & 13 & 15 \\
\hline Total no. & 1195 & 297 & 6 & 1498 & 1090 & $38 \overline{6}$ & 22 & 1498 \\
\hline $\begin{array}{l}\text { Net reclassification } \\
\text { improvement (\%) }\end{array}$ & & 3.48 & & & & -0.89 & & \\
\hline$P$ & & 0.29 & & & & 0.75 & & \\
\hline $\begin{array}{l}\text { Integrated discrimination } \\
\text { improvement (\%) }\end{array}$ & & 0.30 & & & & 0.16 & & \\
\hline$P$ & & 0.05 & & & & 0.13 & & \\
\hline \multicolumn{9}{|l|}{ Men } \\
\hline \multicolumn{9}{|c|}{ Subjects in whom CVD developed } \\
\hline 0 to $<10 \%$ risk & 24 & 1 & 0 & 25 & 58 & 4 & 0 & 62 \\
\hline 10 to $<20 \%$ risk & 8 & 81 & 1 & 90 & 3 & 47 & 1 & 51 \\
\hline$\geq 20 \%$ risk & 0 & 1 & 3 & 4 & 0 & 2 & 4 & 6 \\
\hline Total no. & 32 & 83 & 4 & 119 & 61 & 53 & 5 & 119 \\
\hline \multicolumn{9}{|c|}{ Subjects in whom CVD did not develop } \\
\hline 0 to $<10 \%$ risk & 568 & 30 & 0 & 598 & 834 & 20 & 0 & 854 \\
\hline 10 to $<20 \%$ risk & 98 & 490 & 15 & 603 & 54 & 275 & 3 & 332 \\
\hline$\geq 20 \%$ risk & 0 & 5 & 13 & 18 & 0 & 11 & 22 & 33 \\
\hline Total no. & 666 & 525 & 28 & 1219 & 888 & 306 & 25 & 1219 \\
\hline $\begin{array}{l}\text { Net reclassification } \\
\text { improvement (\%) }\end{array}$ & & -1.12 & & & & 3.45 & & \\
\hline$P$ & & 0.69 & & & & 0.20 & & \\
\hline $\begin{array}{l}\text { Integrated discrimination } \\
\text { improvement }(\%)\end{array}$ & & 0.42 & & & & 0.17 & & \\
\hline$P$ & & 0.05 & & & & 0.17 & & \\
\hline
\end{tabular}

ASCVD, atherosclerotic cardiovascular disease risk score; CVD, cardiovascular disease; RRS, Reynolds risk score; TSH, thyroid-stimulating hormone.

the subjects the test results at the time of inclusion. Fourth, data on the use of aspirin, which could affect CV outcomes, was not available. However, the possibility of taking aspirin in the $\mathrm{SCH}$ group would be similar or greater than in the euthyroid group because of the worse metabolic profile in the former group. Therefore, the protective effect of aspirin would not jeopardise the study results demonstrating increasing $\mathrm{CV}$ risk in the $\mathrm{SCH}$ group. Fifth, we could not assess the changes in thyroid function because thyroid function testing was performed only at baseline. Although raised TSH is frequently transient, we recently reported that $\mathrm{SCH}$ individuals who converted to euthyroidism were still prone to develop SCH again (12). Moreover, a recent study using both multiple and first TSH data failed to show increased CV risk in older adults with SCH (43). Finally, even with adjustments for representative global CV risk scoring systems with TSH levels, the possibility of residual confounding variables remains, particularly for the intermediate-risk individuals, young women and in the assessment of short-term cardiovascular risk $(9,44)$.

In summary, an elevation of serum TSH levels significantly increased the $\mathrm{CV}$ risk in men; however, TSH levels did not improve the prediction of the $\mathrm{CV}$ risk when combined with the clinical risk factors commonly used in either women or men. Our data indicate that TSH screening might not be recommended for the prediction of $\mathrm{CV}$ risk for asymptomatic individuals. 
Supplementary data

This is linked to the online version of the paper at http://dx.doi.org/10.1530/ EJE-14-0464.

\section{Declaration of interest}

The authors declare that there is no conflict of interest that could be perceived as prejudicing the impartiality of the research reported.

\section{Funding}

This work was supported in part by Korea Centers for Disease Control and Prevention (contracts 2001347-6111-221, 2002-347-6111-221, 2003-347-6111-221，2004-E71001-00，2005-E71001-00，2006-E71006-00, 2007-E71003-00， 2008-E71005-00， 2009-E71007-00， 2010-E71004-00， 2011-E71008-00, and 2012-E71008-00).

\section{Author contribution statement}

Drs Y J Park and N H Cho had full access to all of the data in the study and take responsibility for the integrity of the data and the accuracy of the data analysis. Study concept and design: T H Kim, K S Park, H C Jang, N H Cho, and $\mathrm{Y}$ J Park. Acquisition of data: J C Bae, S H Choi, S Lim, and M K Lee. Analysis and interpretation of data: T H Kim, H S Choi, J H Moon, H K Kim, and D J Park. Drafting of the manuscript: T H Kim, S Lim, H C Jang, N H Cho, and $Y$ J Park. Critical revision of the manuscript for important intellectual content: H S Choi, J C Bae, J H Moon, H K Kim, S H Choi, D J Park, K S Park, and M K Lee. Statistical analysis: T H Kim, H S Choi, S Lim, N H Cho, and Y J Park. Obtaining funding: $\mathrm{N} \mathrm{H} \mathrm{Cho.} \mathrm{Administrative,} \mathrm{technical,} \mathrm{or} \mathrm{material}$ support: J C Bae, J H Moon, S H Choi, H C Jang, and Y J Park. Supervision: D J Park, K S Park, M K Lee, and N H Cho.

\section{References}

1 Minino AM, Murphy SL, Xu J \& Kochanek KD. Deaths: final data for 2008. National Vital Statistics Reports 201159 1-126.

2 Korea National Statistical Office. Annual Report on the Cause of Death Statistics in 2012. Seoul: Korea National Statistical Office, 2013.

3 Ridker PM, Buring JE, Rifai N \& Cook NR. Development and validation of improved algorithms for the assessment of global cardiovascular risk in women: the Reynolds risk score. Journal of the American Medical Association 2007297 611-619. (doi:10.1001/jama.297.6.611)

4 Stone NJ, Robinson JG, Lichtenstein AH, BaireyMerz CN, Blum CB, Eckel RH, Goldberg AC, Gordon D, Levy D, Lloyd-Jones DM et al. 2013 ACC/AHA guideline on the treatment of blood cholesterol to reduce atherosclerotic cardiovascular risk in adults: a report of the American College of Cardiology/American Heart Association Task Force on Practice Guidelines. Journal of the American College of Cardiology 201463 2889-2934. (doi:10.1016/j.jacc.2013.11.002)

5 Asvold BO, Bjoro T, Nilsen TI \& Vatten LJ. Association between blood pressure and serum thyroid-stimulating hormone concentration within the reference range: a population-based study. Journal of Clinical Endocrinology and Metabolism 200792 841-845. (doi:10.1210/ jc.2006-2208)

6 Asvold BO, Vatten LJ, Nilsen TI \& Bjoro T. The association between TSH within the reference range and serum lipid concentrations in a population-based study. The HUNT Study. European Journal of Endocrinology 2007156 181-186. (doi:10.1530/eje.1.02333)

7 Cooper DS \& Biondi B. Subclinical thyroid disease. Lancet 2012379 1142-1154. (doi:10.1016/S0140-6736(11)60276-6)
8 Leese GP, Flynn RV, Jung RT, Macdonald TM, Murphy MJ \& Morris AD. Increasing prevalence and incidence of thyroid disease in Tayside, Scotland: the Thyroid Epidemiology Audit and Research Study (TEARS). Clinical Endocrinology 200868 311-316.

9 Tseng FY, Lin WY, Lin CC, Lee LT, Li TC, Sung PK \& Huang KC. Subclinical hypothyroidism is associated with increased risk for all-cause and cardiovascular mortality in adults. Journal of the American College of Cardiology 201260 730-737. (doi:10.1016/j.jacc.2012.03.047)

10 Choi SH, Kim TH, Lim S, Park KS, Jang HC \& Cho NH. Hemoglobin A1c as a diagnostic tool for diabetes screening and new-onset diabetes prediction: a 6-year community-based prospective study. Diabetes Care 201134 944-949. (doi:10.2337/dc10-0644)

11 Cho NH, Choi HS, Kim KW, Kim HL, Lee SY, Choi SH, Lim S, Park YJ, Park do J, Jang HC et al. Interaction between cigarette smoking and iodine intake and their impact on thyroid function. Clinical Endocrinology 201073 264-270.

12 Kim TH, Kim KW, Ahn HY, Choi HS, Won H, Choi Y, Cho SW, Moon JH, Yi KH, Park do J et al. Effect of seasonal changes on the transition between subclinical hypothyroid and euthyroid status. Journal of Clinical Endocrinology and Metabolism 201398 3420-3429. (doi:10.1210/jc.2013-1607)

13 Rodondi N, den Elzen WP, Bauer DC, Cappola AR, Razvi S, Walsh JP, Asvold BO, Iervasi G, Imaizumi M, Collet TH et al. Subclinical hypothyroidism and the risk of coronary heart disease and mortality. Journal of the American Medical Association 2010304 1365-1374. (doi:10.1001/jama.2010.1361)

14 Giri A, Edwards TL, LeGrys VA, Lorenz CE, Funk MJ, Schectman R, Heiss G, Robinson JG \& Hartmann KE. Subclinical hypothyroidism and risk for incident ischemic stroke among postmenopausal women. Thyroid 201424 1210-1217. (doi:10.1089/thy.2014.0106)

15 American Diabetes Association. Executive summary: standards of medical care in diabetes - 2013. Diabetes Care 201336 (Suppl 1) S4-S10. (doi:10.2337/dc13-S004)

16 Berry SD, Samelson EJ, Pencina MJ, McLean RR, Cupples LA, Broe KE \& Kiel DP. Repeat bone mineral density screening and prediction of hip and major osteoporotic fracture. Journal of the American Medical Association 2013310 1256-1262. (doi:10.1001/jama.2013.277817)

17 Rhee CM, Alexander EK, Bhan I \& Brunelli SM. Hypothyroidism and mortality among dialysis patients. Clinical Journal of the American Society of Nephrology 20138 593-601. (doi:10.2215/CJN.06920712)

18 Pencina MJ, D'Agostino RB Sr, D'Agostino RB Jr \& Vasan RS. Evaluating the added predictive ability of a new marker: from area under the ROC curve to reclassification and beyond. Statistics in Medicine 200827 157-172. (doi:10.1002/sim.2929)

19 U.S. Preventive Services Task Force. Screening for thyroid disease: recommendation statement. Annals of Internal Medicine 2004140 125-127. (doi:10.7326/0003-4819-140-2-200401200-00014)

20 Franklyn JA \& Boelaert K. Subclinical thyroid disease: where is the evidence? Lancet Diabetes \& Endocrinology 2013 172-173. (doi:10.1016/S2213-8587(13)70030-5)

21 Meyerovitch J, Rotman-Pikielny P, Sherf M, Battat E, Levy Y \& Surks MI. Serum thyrotropin measurements in the community: five-year follow-up in a large network of primary care physicians. Archives of Internal Medicine 2007167 1533-1538. (doi:10.1001/archinte. 167.14.1533)

22 Gharib H, Tuttle RM, Baskin HJ, Fish LH, Singer PA \& McDermott MT. Subclinical thyroid dysfunction: a joint statement on management from the American Association of Clinical Endocrinologists, the American Thyroid Association, and the Endocrine Society. Journal of Clinical Endocrinology and Metabolism 200590 581-585 discussion 586-587. (doi:10.1210/jc.2004-1231)

23 Nakajima Y, Yamada M, Akuzawa M, Ishii S, Masamura Y, Satoh T, Hashimoto K, Negishi M, Shimomura Y, Kobayashi I et al. Subclinical hypothyroidism and indices for metabolic syndrome in Japanese women: one-year follow-up study. Journal of Clinical Endocrinology and Metabolism 201398 3280-3287. (doi:10.1210/jc.2013-1353) 
24 Meigs JB, Shrader P, Sullivan LM, McAteer JB, Fox CS, Dupuis J, Manning AK, Florez JC, Wilson PW, D'Agostino RB Sr et al. Genotype score in addition to common risk factors for prediction of type 2 diabetes. New England Journal of Medicine 2008359 2208-2219. (doi:10.1056/NEJMoa0804742)

25 Park YJ, Lee YJ, Choi SI, Chun EJ, Jang HC \& Chang HJ. Impact of subclinical hypothyroidism on the coronary artery disease in apparently healthy subjects. European Journal of Endocrinology 2011165 115-121. (doi:10.1530/EJE-11-0014)

26 Marfella R, Ferraraccio F, Rizzo MR, Portoghese M, Barbieri M, Basilio C, Nersita R, Siniscalchi LI, Sasso FC, Ambrosino I et al. Innate immune activity in plaque of patients with untreated and L-thyroxine-treated subclinical hypothyroidism. Journal of Clinical Endocrinology and Metabolism 201196 1015-1020. (doi:10.1210/jc.2010-1382)

27 Pasqualetti G, Tognini S, Polini A, Caraccio N \& Monzani F. Is subclinical hypothyroidism a cardiovascular risk factor in the elderly? Journal of Clinical Endocrinology and Metabolism 201398 2256-2266. (doi:10.1210/jc.2012-3818)

28 Gussekloo J, van Exel E, de Craen AJ, Meinders AE, Frolich M \& Westendorp RG. Thyroid status, disability and cognitive function, and survival in old age. Journal of the American Medical Association 2004292 2591-2599. (doi:10.1001/jama.292.21.2591)

29 Garber JR, Cobin RH, Gharib H, Hennessey JV, Klein I, Mechanick JI, Pessah-Pollack R, Singer PA \& Woeber KA. Clinical practice guidelines for hypothyroidism in adults: cosponsored by the American Association of Clinical Endocrinologists and the American Thyroid Association. Endocrine Practice 201218 988-1028. (doi:10.4158/EP12280.GL)

30 Villar HC, Saconato H, Valente O \& Atallah AN. Thyroid hormone replacement for subclinical hypothyroidism. Cochrane Database of Systematic Reviews 20073 CD003419.

31 Razvi S, Weaver JU, Butler TJ \& Pearce SH. Levothyroxine treatment of subclinical hypothyroidism, fatal and nonfatal cardiovascular events, and mortality. Archives of Internal Medicine 2012172 811-817.

32 Sawin CT, Geller A, Wolf PA, Belanger AJ, Baker E, Bacharach P, Wilson P, Benjamin EJ \& D'Agostino RB. Low serum thyrotropin concentrations as a risk factor for atrial fibrillation in older persons. New England Journal of Medicine 1994331 1249-1252. (doi:10.1056/ NEJM199411103311901)

33 Kvetny J, Heldgaard PE, Bladbjerg EM \& Gram J. Subclinical hypothyroidism is associated with a low-grade inflammation, increased triglyceride levels and predicts cardiovascular disease in males below 50 years. Clinical Endocrinology 200461 232-238. (doi:10.1111/j.13652265.2004.02088.x)

34 Lindeman RD, Romero LJ, Schade DS, Wayne S, Baumgartner RN \& Garry PJ. Impact of subclinical hypothyroidism on serum total homocysteine concentrations, the prevalence of coronary heart disease
(CHD), and CHD risk factors in the New Mexico Elder Health Survey. Thyroid 200313 595-600. (doi:10.1089/105072503322238863)

35 Kim HC, Greenland P, Rossouw JE, Manson JE, Cochrane BB, Lasser NL, Limacher MC, Lloyd-Jones DM, Margolis KL \& Robinson JG. Multimarker prediction of coronary heart disease risk: the Women's Health Initiative. Journal of the American College of Cardiology 201055 2080-2091. (doi:10.1016/j.jacc.2009.12.047)

36 Cook NR \& Ridker PM. Advances in measuring the effect of individual predictors of cardiovascular risk: the role of reclassification measures. Annals of Internal Medicine 2009150 795-802. (doi:10.7326/0003-4819150-11-200906020-00007)

37 Tzoulaki I, Liberopoulos G \& Ioannidis JP. Assessment of claims of improved prediction beyond the Framingham risk score. Journal of the American Medical Association 2009302 2345-2352. (doi:10.1001/ jama.2009.1757)

38 Kim YA \& Park YJ. Prevalence and risk factors of subclinical thyroid disease. Endocrinology and Metabolism 201429 20-29. (doi:10.3803/ EnM.2014.29.1.20)

39 Laurberg P, Pedersen KM, Hreidarsson A, Sigfusson N, Iversen E \& Knudsen PR. Iodine intake and the pattern of thyroid disorders: a comparative epidemiological study of thyroid abnormalities in the elderly in Iceland and in Jutland, Denmark. Journal of Clinical Endocrinology and Metabolism 199883 765-769. (doi:10.1210/jcem.83. 3.4624)

40 Collet TH, Gussekloo J, Bauer DC, den Elzen WP, Cappola AR, Balmer P, Iervasi G, Asvold BO, Sgarbi JA, Volzke H et al. Subclinical hyperthyroidism and the risk of coronary heart disease and mortality. Archives of Internal Medicine 2012172 799-809. (doi:10.1001/ archinternmed.2012.402)

41 Wollenweber FA, Zietemann V, Gschwendtner A, Opherk C \& Dichgans M. Subclinical hyperthyroidism is a risk factor for poor functional outcome after ischemic stroke. Stroke 201344 1446-1448. (doi:10.1161/STROKEAHA.113.000833)

42 Pearce SH, Brabant G, Duntas LH, Monzani F, Peeters RP, Razvi S \& Wemeau JL. ETA guideline: management of subclinical hypothyroidism. European Thyroid Journal 20132 215-228. (doi:10.1159/000356507)

43 Hyland KA, Arnold AM, Lee JS \& Cappola AR. Persistent subclinical hypothyroidism and cardiovascular risk in the elderly: the cardiovascular health study. Journal of Clinical Endocrinology and Metabolism 201398 533-540. (doi:10.1210/jc.2012-2180)

44 Cooney MT, Dudina AL \& Graham IM. Value and limitations of existing scores for the assessment of cardiovascular risk: a review for clinicians. Journal of the American College of Cardiology $2009 \mathbf{5 4}$ 1209-1227. (doi:10.1016/j.jacc.2009.07.020)

Received 7 June 2014

Revised version received 11 August 2014

Accepted 1 September 2014 